\title{
Assessment of the stroke-specific quality-of-life scale in KFHU, Khobar
}

\section{A prospective cross-sectional study}

SarahM.Alotaibi, MBBS, HoriaM.Alotaibi, MBBS,AmiraM.Alolyani, MBBS, FawziahA.AbuDali, MBBS, AlaaK.Alshammari, MBBS, Amani A. Alhwiesh, MBBS, Danya M. Gari, MBBS, SBFM, Inam Khuda M.Q Khuda, MBBS, FCPS, Christopher A. Vallabadoss, MPhil, $P h D$.

\begin{abstract}

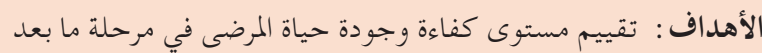

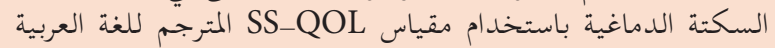

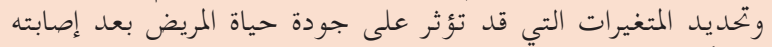
بالسكتة الدماغية.

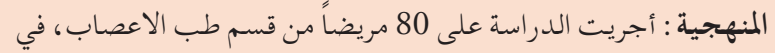

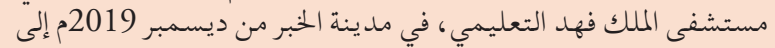

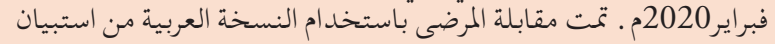
و وباستخدام مقياس mRS-QOL

النتائج : مجموع جودة الحياة لدى العينة المدروسة يصل الى 3.72

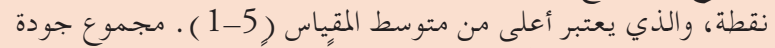

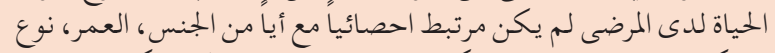

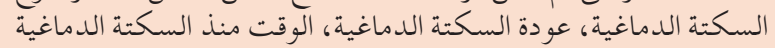

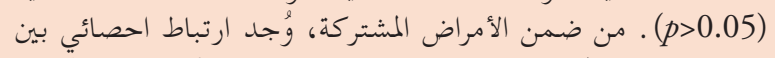

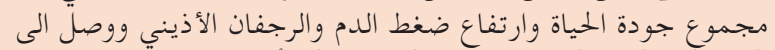

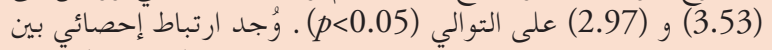

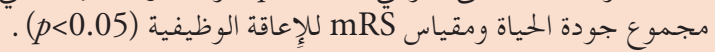

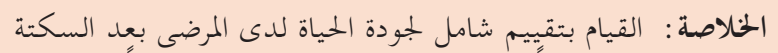

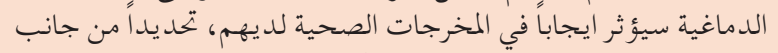

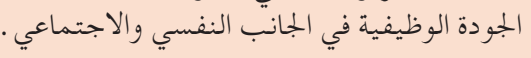

Objectives: To assess the overall and domain-specific quality of life (QOL) in post-stroke patients using the stroke-specific quality of life (SS-QOL) scale and to identify variables that may affect the QOL after stroke.

Methods: A prospective cross-sectional study, included 80 stroke patients, was conducted in the Neurology department at King Fahad Hospital of the University (KFHU), Khobar, Saudi Arabia, from December 2019 to February 2020. Stroke patients were interviewed using the Arabic version of the SSQOL questionnaire and modified Rankin scale (mRS).
Results: The overall quality of life in the surveyed participants was at the level of 3.72 points, which is above the average recognized in the middle of the scale that ranges from 1 to 5 . The overall quality of life was not significantly correlated with sex, age, type of stroke, recurrence of stroke, and time since stroke $(p>0.05)$. Hypertension and atrial fibrillation were the only comorbidities that were determined to be significantly associated with the overall quality of life at the level of (3.53), and (2.97) respectively $(p<0.05)$. There was a statistically significant correlation between the mRS score and the overall quality of life $(p<0.05)$.

Conclusion: Performing a comprehensive assessment of the overall QOL in post-stroke patients will result in better health outcomes, particularly in terms of quality of functioning in psycho-social aspects.

\section{Neurosciences 2021; Vol. 26 (2): 171-178 doi: 10.17712/nsj.2021.2.20200126}

From the College of Medicine (Alotaibi $S$, Alotaibi $H$, Alolyani, Abudalli, Alshammari, Alhwiesh), from the Department of Family Medicine (Gari); and from the Deanship for Quality and Development (Vallabadoss), Department of Neurology (Khuda), College of Medicine, Imam Abdulrahman bin Faisal University, Dammam, Kingdom of Saudi Arabia

Received 6th 11th August 2020. Accepted 7th November 2020.

Address correspondence and reprint request to: Dr. Sarah M. Alotaibi, College of Medicine, Imam Abdulrahman bin Faisal University, Dammam, Kingdom of Saudi Arabia.E-mail: Sara_alotaibi2@hotmail.com

ORCID ID: https://orcid.org/0000-0002-0024-262X

Stroke is a disease that is known by its focal neurologic $\mathcal{O}_{\text {deficit. }}{ }^{1}$ It occurs when there is a disruption of the blood flow to the brain either by a clot, causing ischemic stroke or by a rupture of the blood vessels, causing hemorrhagic stroke. ${ }^{2}$ It is experienced by approximately 
15 million people worldwide and it is considered to be the second cause of mortality. Among these people, 5 million die and another 5 million live with lifelong disability, which creates a major economic and social burden. The number of cases of stroke in Saudi Arabia is increasing and becoming a debilitating reason for death and disability. Research on the incidence and prevalence of stroke in Saudi Arabia is still lacking. There is only one study conducted in Saudi Arabia in the last 10 years, which states that stroke's prevalence is 29 per 100,000 each year. ${ }^{2,3}$

Stroke affects the quality of life (QOL) of patients owing to its related cognitive, physical and functional consequences, such as restrictions in mobility, language impairment and depression. ${ }^{4,5}$ Although stroke causes extensive functional impairment, the objective methods of evaluation usually fail to assess the subjective impact of these impairments. ${ }^{6}$ The Health-related QOL (HR-QOL) is a term used to evaluate a person's wellbeing including physical, psychological, functional, and social aspects. ${ }^{7}$ There are various instruments to assess HR-QOL, most of which are based on subjective self-administered questionnaires. Among these instruments is the stroke-specific QOL (SS-QOL) scale, which was established as a multi-dimensional tool for various effects in post-stroke patients. ${ }^{8}$

Up to date, there have been 4 studies conducted in Saudi Arabia on the assessment of QOL in post-stroke patients. ${ }^{9-12}$ Two of them were conducted in Jeddah; in these studies, the researchers studied QOL among stroke patients using the HR-QOL scale. ${ }^{9,10}$ The other 2 studies were conducted in Al Khobar; the first study studied the psychometric properties of an Arabic version of the fatigue severity scale (FSS), ${ }^{11}$ while the second study measured QOL using SS-QOL and compared its variables such as socio-demographic factors, type of stroke, time passed since the stroke, affected body side, and the living status of stroke patients. ${ }^{12}$ However, QOL in post-stroke patients evaluated using SS-QOL has not been studied yet in terms of other variables such as recurrence of stroke, degree of physical disability, comorbidities, and risk factors. Therefore, the aim of this study is to assess the overall and domain-specific QOL in post-stroke patients using the SS-QOL scale and to identify variables that may affect the quality of life after stroke. The quality of life in post-stroke

Disclosure. Authors have no conflict of interests, and the work was not supported or funded by any drug company. patients has a statistically significant relationship with the type of stroke, duration since the last event, patient demographics, comorbidities, and degree of physical disability.

Methods. A prospective cross-sectional study was conducted in the Neurology Department, King Fahad Hospital of the University (KFHU), Al Khobar, Saudi Arabia, from December 2019 to February 2020. Approval for this study was provided by the institutional review board at Imam Abdulrahman bin Faisal University (IRB \#: IRB-UGS-2019-010375).

The sample size was 80 stroke patients (male $=46$, female $=34$ ) and was collected by convenient sampling technique because the duration of patients' recruitment was limited to 3 months. Inclusion criteria were as follows: both genders, older than 18 years, and who were diagnosed with stroke for a minimum of 6 months before this study. We excluded patients who were demented, unable to speak, failed to complete the questionnaire, or to understand its contents and hard to reach them.

The data were collected using a combination of a self-administered questionnaire and an interview of stroke patients who attended the outpatient clinics in KFHU. Moreover, the missing data were obtained from medical records. The intended questionnaire, which has been previously used and validated, is the SS-QOL scale version 2.0 developed by Williams LS; it includes 49 items that are composed of 12 domains including vision, language, thinking, personality, upper extremity function, mobility, work and productivity, mood, energy, self-care, family roles, and social roles. ${ }^{13}$ Each domain has the maximum score of $5 .{ }^{1-5}$ Another tool used includes mRS, which is a 6-point scale that is used to measure the degree of dependency after stroke. ${ }^{14}$

Statistical analysis. The data were entered and analyzed for validity and reliability using SPSS version 21 (IBMCorp, Armonk, NY, USA). The Arabic translation process of the SS-QOL scale followed the standard guidelines: forward backward translation, expert validation, and field testing (pilot study). ${ }^{15}$ The internal consistency of the total SS-QOL-A and the 12 domains score was evaluated by calculating Cronbach's alpha; and it was 0.97 , which is $>0.7$, and makes the questionnaire valid. ${ }^{15}$ The test-retest reliability of the translated questionnaire was assessed by intra-class correlation coefficients (ICCs), which should surpass 0.7 in the subsection domain. ${ }^{8}$ Pearson correlation (rp) was used to determine the relation of each item to its domain, and it is considered when the item was moderately correlated with its domain $(\mathrm{rp} \geq 0.40){ }^{15}$ 
The Chi-squared test was used to compare categorical variables, and the $p$-value $<0.05$ was considered to be significant.

Results. Study participants. The surveyed group consisted of 80 patients; $57.5 \%$ of them were males, whereas $42.5 \%$ were females. Regarding the age group, $26.3 \%$ were younger than 45 years old, while $23.7 \%$ were between the age of 45 and 55, 25\% were between the age of 56 and 65 , and the remaining $25 \%$ were older than 65 years old. The average age of the participants was 55.53 years (the range of $26-90$ years) (Table 1 ).

Quality of life of the participants. The overall QOL of the surveyed participants was at the level of 3.72 points $(\mathrm{SD}=1.02)$, which is above the average (3 points is the middle of the scale that ranges from 1 to 5$)$. The results ranged between 0.98 and 4.90 points and half of the participants scored below 4.02 points. QOL of patients after stroke was the highest in language (mean=4.15), mood (mean=4.07), and upper extremity function (mean=4.01). The lowest QOL was in mobility $($ mean=3.37) and energy (3.41) (Table 2).

Quality of life of the participants according to gender. The analysis using an independent t-test showed no statistically significant difference between males and females in all domains; energy $(p=0.93)$, family roles $(p=0.67)$, language $(p=0.32)$, mobility $(p=0.38)$, mood $(p=0.64)$, personality $(p=0.41)$, self-care $(p=0.60)$, social role $(p=0.65)$, thinking $(p=0.80)$, upper extremity function $(p=0.45)$, vision $(p=0.57)$, and work/ productivity $(p=0.59)$. The overall QOL was almost the same in females $($ mean $=3.73)$ and males $($ mean $=3.71$, $p=0.94$ ).

Quality of life of the participants according to age. Qualaity of life was the highest among patients who were younger than 45 years old compared to other age groups concerning mobility (mean $=4.04, p=0.007$ ), self-care (mean $=4.58, p=0.02)$, and work/productivity (mean=4.60, $p=0.008$ ). However, the remaining domains of QOL between the age groups are statistically insignificant $(p>0.05)$ (Table 3).

Quality of life of the participants according to the type of stroke. Ischemic stroke occurred in 75 of the patients (93.8\%), while 5 of them (6.2\%) suffered from hemorrhagic stroke. Statistical analysis revealed higher QOL in patients after ischemic stroke than in those after haemorrhagic stroke in 2 domains only: mood (4.17) $(p=0.029)$, and work/productivity (3.87) $(p=0.023)$. However, the remaining domains of QOL in ischemic and haemorrhagic groups were statistically insignificant $(p>0.05)$ (Table 4).

Quality of life of the participants according to time since stroke. According to the time since stroke,
Table 1 - Demographic characteristics of the participants.

\begin{tabular}{|c|c|}
\hline Characteristics & Variable \\
\hline \multicolumn{2}{|l|}{ Gender } \\
\hline Male & $46(57.5)$ \\
\hline Female & $34 \quad(42.5)$ \\
\hline Average age, y (range) & $55.53(26-90)$ \\
\hline \multicolumn{2}{|l|}{ Age } \\
\hline$<45$ years & $21(26.3)$ \\
\hline $45-55$ years & $19(23.7)$ \\
\hline $56-65$ years & $20(25.0)$ \\
\hline 65 years & $20(25.0)$ \\
\hline \multicolumn{2}{|l|}{ Stroke subtype } \\
\hline Ischemic & $75(93.8)$ \\
\hline haemorrhagic & $5 \quad(6.2)$ \\
\hline \multicolumn{2}{|l|}{ Recurrence } \\
\hline Not recurrent & $62(77.5)$ \\
\hline Recurrent & $18(22.5)$ \\
\hline \multicolumn{2}{|l|}{ Duration } \\
\hline$<1$ year & $32(40.0)$ \\
\hline $1-2$ years & $29(36.3)$ \\
\hline $3-5$ years & $11(13.8)$ \\
\hline$>5$ years & $8(10.0)$ \\
\hline \multicolumn{2}{|l|}{ Comorbidities and risk factors } \\
\hline Hypertension & $59(73.8)$ \\
\hline Diabetes mellitus & $46(58.7)$ \\
\hline Dyslipidemia & $32(40.0)$ \\
\hline Obesity & $15(18.8)$ \\
\hline Ischemic heart disease & $13(16.0)$ \\
\hline Smoking & $12(15.0)$ \\
\hline Atrial fibrillation & $7(8.75)$ \\
\hline \multicolumn{2}{|l|}{ Rankin scale } \\
\hline $0-2$ points & $46(57.5)$ \\
\hline $3-5$ points & $34(42.5)$ \\
\hline
\end{tabular}

Table 2 - Quality of life of the participants.

\begin{tabular}{|c|c|c|c|c|c|c|}
\hline Quality of life & $\mathrm{N}$ & Mean & Median & Min. & Max. & SD \\
\hline Energy & 80 & 3.41 & 3.66 & 1.0 & 5.0 & 1.40 \\
\hline Family roles & 80 & 3.74 & 4.00 & 1.0 & 5.0 & 1.34 \\
\hline Language & 80 & 4.15 & 5.00 & 1.0 & 5.0 & 1.28 \\
\hline Mobility & 80 & 3.37 & 3.66 & 1.0 & 5.0 & 1.43 \\
\hline Mood & 80 & 4.07 & 4.70 & 1.0 & 5.0 & 1.53 \\
\hline Personality & 80 & 3.73 & 4.00 & 1.0 & 5.0 & 1.36 \\
\hline Self-care & 80 & 3.91 & 4.90 & 1.0 & 5.0 & 1.48 \\
\hline Social role & 80 & 3.66 & 4.00 & 1.0 & 5.0 & 1.38 \\
\hline Thinking & 80 & 3.84 & 4.33 & 1.0 & 5.0 & 1.39 \\
\hline $\begin{array}{l}\text { Upper extremity } \\
\text { function }\end{array}$ & 80 & 4.01 & 5.00 & 1.0 & 5.0 & 1.48 \\
\hline Vision & 80 & 3.75 & 4.00 & 1.0 & 5.0 & 1.37 \\
\hline $\begin{array}{l}\text { Work/ } \\
\text { productivity }\end{array}$ & 80 & 3.77 & 4.50 & 1.0 & 5.0 & 1.47 \\
\hline SS-QOL & 80 & 3.72 & 4.02 & 0.98 & 4.90 & 1.02 \\
\hline
\end{tabular}

$\mathrm{N}$ : number, Min: minimum, Max: maximum, SD: standard deviation, SS-QOL: stroke-specific quality-of-life 
Table 3 - Quality of life of the participants according to age.

\begin{tabular}{lccccccccc}
\hline \multirow{2}{*}{ Age } & \multicolumn{2}{c}{$<$ years old } & \multicolumn{2}{c}{$45-55$ years old } & \multicolumn{2}{c}{ 56-65 years old } & \multicolumn{2}{c}{$>$ 65 years old } & P-value \\
& Mean & SD & Mean & SD & Mean & SD & Mean & SD & \\
\hline Energy & 3.54 & 1.22 & 3.40 & 1.44 & 3.43 & 1.54 & 3.28 & 1.47 & 0.95 \\
Family roles & 4.06 & 1.29 & 3.54 & 1.52 & 3.88 & 1.22 & 3.45 & 1.34 & 0.43 \\
Language & 4.62 & 0.82 & 4.38 & 1.28 & 3.78 & 1.48 & 3.82 & 1.35 & 0.08 \\
Mobility & $4.04^{*}$ & 0.99 & $3.32^{*}$ & 1.44 & $3.56^{*}$ & 1.42 & $2.55^{*}$ & 1.48 & $0.007^{*}$ \\
Mood & 4.17 & 1.15 & 3.84 & 1.47 & 4.44 & 2.05 & 3.83 & 1.33 & 0.54 \\
Personality & 3.71 & 1.43 & 3.63 & 1.45 & 3.90 & 1.35 & 3.68 & 1.29 & 0.93 \\
Self-care & $4.58^{*}$ & 0.81 & $3.98^{*}$ & 1.62 & $3.90^{*}$ & 1.52 & $3.17^{*}$ & 1.58 & $0.02^{*}$ \\
Social roles & 4.06 & 1.13 & 3.64 & 1.67 & 3.48 & 1.23 & 3.45 & 1.45 & 0.46 \\
Thinking & 4.06 & 1.08 & 3.70 & 1.57 & 4.06 & 1.40 & 3.53 & 1.50 & 0.53 \\
Upper extremity function & 4.68 & 0.71 & 4.05 & 1.59 & 3.84 & 1.69 & 3.45 & 1.59 & 0.05 \\
Vision & 3.95 & 1.25 & 3.42 & 1.79 & 3.95 & 1.32 & 3.68 & 1.08 & 0.57 \\
Work/productivity & $4.60^{*}$ & 0.78 & $3.35^{*}$ & 1.77 & $3.90^{*}$ & 1.36 & $3.20^{*}$ & 1.48 & $0.008^{*}$ \\
SS-QOL & 4.13 & 0.56 & 3.65 & 1.25 & 3.76 & 1.05 & 3.32 & 1.02 & 0.08 \\
\hline
\end{tabular}

SD: standard deviation, SS-QOL: stroke-specific quality of life, ${ }^{*} p$-value is significant at $<0.05$

the majority of patients (example, 40\%) had a stroke less than one year ago, while $36.3 \%$ patients had a stroke between one to 2 years ago. In the group of 11 (13.75\%) participants, stroke occurred between 3 to 5 years ago, whereas $10 \%$ participants had a stroke more than five years ago. The analysis revealed no statistically significant difference between the time passed since the stroke and the overall QOL ( $p=0.44)$.

Quality of life of the participants according to the recurrence of stroke. When addressing the recurrence of stroke of the surveyed patients, we determined that for the majority of patients it was the first stroke (example $77.5 \%$ ), while only $22.5 \%$ of patients had the history of recurrent stroke. Statistical analysis revealed higher QOL in patients with non-recurrent stroke compared to patients with recurrent stroke in only 2 domains: mood $($ mean $=4.29)$ and social roles $($ mean=3.84). However, the remaining domains of QOL between the recurrent and non-recurrent groups are statistically insignificant $(p>0.05)$ (Table 5).

Quality of life of the participants according to comorbidities and risk factors. Regarding the comorbidities in post-stroke survival, we determined that the main associated diseases among these patients were hypertension $(73.8 \%)$, diabetes mellitus (58.8\%), and dyslipidemia (40\%). The overall QOL is higher in patients with hypertension (mean=3.53, $p=0.004$ ) compared to patients with atrial fibrillation (mean $=2.97$, $p=0.04$ ). In hypertensive patients, the affected domains included family roles (3.51), mobility (0.012), self-care $($ mean $=3.14)$, social roles $($ mean $=3.46)$, upper extremity function $($ mean $=3.77)$, vision $($ mean $=3.503)$, and work $/$ productivity $(\operatorname{mean}=3.48)$. Similar to hypertension, the affected domains in atrial fibrillation patients included social roles (2.60), vision (2.85), and work/ productivity (2.71). Whereas the mood (mean $=2.65, p=0.009)$ and personality (mean $=2.71, p=0.03$ ) domains were affected only in participants with atrial fibrillation. Moreover, the vision domain (3.089) was significantly affected in obese patients $(p=0.03)$. The remaining domains and the overall QOL in obese patients are statistically insignificant $(p>0.05)$ (Table 6).

Quality of life of the participants according to the $m R S$ score. There is a statistically significant correlation between the mRS score and all domains of QOL; energy $(p=0.001)$, family roles $(p=0.014)$, language $(p=0.010)$, mobility $(p=0.001), \operatorname{mood}(p=0.018)$, personality $(p=0.014)$, self-care $(p=0.001)$, social roles $(p=0.003)$, thinking ( $p=0.002)$, upper extremity function $(p=0.001)$, vision $(p=0.042)$, and work/ productivity $(p=0.001)$. There is a moderate negative linear correlation between the mRS score and SS-QOL

Discussion. Stroke affects patients' wellbeing, health, and QOL. Over the years, there have been improvements in the early management of stroke, interventions, and health care. These measures contributed to higher survival rates and better outcomes. However, many stroke survivors have to cope with physical, cognitive, and functional sequela such as aphasia, depression, emotional disturbance, and muscle weakness. ${ }^{16}$ 
Table 4 - Quality of life of the participants according to type of stroke.

\begin{tabular}{|c|c|c|c|c|}
\hline Type & $\mathrm{N}$ & Mean & SD & $P$-value \\
\hline \multicolumn{5}{|l|}{ Energy } \\
\hline Ischemic & 75 & 3.48 & 1.36 & \multirow{2}{*}{0.094} \\
\hline Haemorrhagic & 5 & 2.40 & 1.67 & \\
\hline \multicolumn{5}{|l|}{ Family roles } \\
\hline Ischemic & 75 & 3.77 & 1.31 & \multirow{2}{*}{0.356} \\
\hline Haemorrhagic & 5 & 3.20 & 1.78 & \\
\hline \multicolumn{5}{|l|}{ Language } \\
\hline Ischemic & 75 & 4.17 & 1.27 & \multirow{2}{*}{0.572} \\
\hline Haemorrhagic & 5 & 3.84 & 1.49 & \\
\hline \multicolumn{5}{|l|}{ Mobility } \\
\hline Ischemic & 75 & 3.43 & 1.41 & \multirow{2}{*}{0.191} \\
\hline Haemorrhagic & 5 & 2.56 & 1.50 & \\
\hline \multicolumn{5}{|l|}{ Mood } \\
\hline Ischemic & 75 & 4.17 & 1.49 & \multirow{2}{*}{$0.029^{*}$} \\
\hline Haemorrhagic & 5 & 2.64 & 1.47 & \\
\hline \multicolumn{5}{|l|}{ Personality } \\
\hline Ischemic & 75 & 3.80 & 1.33 & \multirow{2}{*}{0.071} \\
\hline Haemorrhagic & 5 & 2.66 & 1.49 & \\
\hline \multicolumn{5}{|l|}{ Self-care } \\
\hline Ischemic & 75 & 3.98 & 1.44 & \multirow{2}{*}{0.137} \\
\hline Haemorrhagic & 5 & 2.96 & 1.93 & \\
\hline \multicolumn{5}{|l|}{ Social Role } \\
\hline Ischemic & 75 & 3.73 & 1.35 & \multirow{2}{*}{0.075} \\
\hline Haemorrhagic & 5 & 2.60 & 1.51 & \\
\hline \multicolumn{5}{|l|}{ Thinking } \\
\hline Ischemic & 75 & 3.80 & 1.41 & \multirow{2}{*}{0.305} \\
\hline Haemorrhagic & 5 & 4.46 & 0.76 & \\
\hline \multicolumn{5}{|c|}{ Upper extremity function } \\
\hline Ischemic & 75 & 4.07 & 1.46 & \multirow{2}{*}{0.185} \\
\hline Haemorrhagic & 5 & 3.16 & 1.80 & \\
\hline \multicolumn{5}{|l|}{ Vision } \\
\hline Ischemic & 75 & 3.72 & 1.40 & \multirow{2}{*}{0.462} \\
\hline Haemorrhagic & 5 & 4.20 & 0.83 & \\
\hline \multicolumn{5}{|l|}{ Work/productivity } \\
\hline Ischemic & 75 & 3.87 & 1.45 & \multirow{2}{*}{$0.023^{*}$} \\
\hline Haemorrhagic & 5 & 2.33 & 1.02 & \\
\hline \multicolumn{5}{|l|}{$S S-Q O L$} \\
\hline Ischemic & 75 & 3.77 & 1.01 & \multirow{2}{*}{0.094} \\
\hline Haemorrhagic & 5 & 2.98 & 0.87 & \\
\hline
\end{tabular}

SS-QOL - stroke specific quality of life scale, SD - standard deviation, ${ }^{*} P$-value is significant at $<0.05$

This study aims to assess QOL after stroke in patients who were diagnosed with stroke for a minimum of 6 months before this study using the SS-QOL scale and to identify variables that can affect QOL after stroke in terms of socio-demographic factors, type of stroke, recurrence of stroke, time passed since stroke, mRS, comorbidities, and risk factors. Based on the obtained results, it is determined that the overall QOL is relatively high. In this study, it was determined that the mean SS-QOL of 80 patients was (at the level of 3.7253,) which is above the average score of 3 . In addition, the mean
Table 5 - Quality of life of the participants according to the recurrence of stroke.

\begin{tabular}{|c|c|c|c|c|c|}
\hline \multirow{2}{*}{$\begin{array}{l}\text { Recurrence of } \\
\text { stroke }\end{array}$} & \multicolumn{2}{|c|}{$\begin{array}{c}\text { Recurrent } \\
(\mathrm{n}=18)\end{array}$} & \multicolumn{2}{|c|}{$\begin{array}{l}\text { Non-recurrent } \\
\quad(n=62)\end{array}$} & \multirow{2}{*}{$P$-value } \\
\hline & Mean & SD & Mean & SD & \\
\hline Energy & 3.38 & 1.37 & 3.42 & 1.41 & 0.92 \\
\hline Family roles & 3.48 & 1.05 & 3.81 & 1.41 & 0.28 \\
\hline Language & 4.04 & 1.11 & 4.19 & 1.33 & 0.67 \\
\hline Mobility & 3.47 & 1.35 & 3.35 & 1.45 & 0.75 \\
\hline Mood & $3.32^{*}$ & 1.37 & $4.29^{*}$ & 1.51 & $0.01^{*}$ \\
\hline Personality & 3.59 & 1.48 & 3.77 & 1.33 & 0.62 \\
\hline Self-care & 3.58 & 1.58 & 4.01 & 1.45 & 0.28 \\
\hline Social roles & $3.05^{*}$ & 1.63 & $3.84^{*}$ & 1.25 & $0.03^{*}$ \\
\hline Thinking & 3.53 & 1.57 & 3.93 & 1.33 & 0.28 \\
\hline $\begin{array}{l}\text { Upper } \\
\text { extremity } \\
\text { function }\end{array}$ & 3.78 & 1.53 & 4.08 & 1.48 & 0.46 \\
\hline Vision & 4.07 & 1.40 & 3.66 & 1.36 & 0.27 \\
\hline $\begin{array}{l}\text { Work/ } \\
\text { productivity }\end{array}$ & 3.63 & 1.58 & 3.82 & 1.45 & 0.62 \\
\hline SS-QOL & 3.49 & 0.90 & 3.79 & 1.04 & 0.28 \\
\hline
\end{tabular}

score for each domain in the SS-QOL scale was above the average score, which suggested that most patients were coping positively with stroke-related impairments. Regarding the domains, the language domain was the least affected, which could be due to language recovery during the first few weeks-months considering that this study included patients with a minimum of 6 months post-stroke. In a highly cited article by Pedersen et $\mathrm{al},{ }^{17}$ most participants who suffered from mild aphasia after stroke recovered within 2 weeks; patients with moderate aphasia recovered within six weeks; for severe aphasia, they recovered within 10 weeks. ${ }^{17}$ The language domain was the least affected, which has been reported in other studies. ${ }^{18,10}$ The mobility domain was the most affected and had the lowest score, which could be due to multiple factors such as, transportation problems or low income leading to altering or delaying rehabilitation and physiotherapy. In a study by Hopman et al, ${ }^{19} 53.8 \%$ of post-stroke patients showed improvement in motor activity as a result of rehabilitation exercises. Therefore, rehabilitation is essential for improving patients' motor activity.

However, a similar study that was conducted in Poland in 2017-2018 assessed the QOL of 80 post-stroke patients using the SS-QOL scale; the overall QOL was below the average 2.64 points $(\mathrm{SD}=0.84)$; the 
Table 6 - Quality of life of the participants according to comorbidities and risk factors.

\begin{tabular}{|c|c|c|c|c|c|c|c|c|c|c|c|c|c|c|}
\hline \multirow[t]{2}{*}{ Comorbidities } & \multicolumn{2}{|c|}{$\begin{array}{c}\text { Hypertension } \\
59(73.8 \%)\end{array}$} & \multicolumn{2}{|c|}{$\begin{array}{l}\text { Diabetes mellitus } \\
\quad 47(58.8 \%)\end{array}$} & \multicolumn{2}{|c|}{$\begin{array}{c}\text { Dyslipidemia } \\
32(40 \%)\end{array}$} & \multicolumn{2}{|c|}{$\begin{array}{c}\text { Obesity } \\
15(18.8 \%)\end{array}$} & \multicolumn{2}{|c|}{$\begin{array}{c}\text { Ischemic disease } \\
\text { heart } \\
13(16.0 \%)\end{array}$} & \multicolumn{2}{|c|}{$\begin{array}{c}\text { Smoking } \\
12(15.0 \%)\end{array}$} & \multicolumn{2}{|c|}{$\begin{array}{l}\text { Atrial fibrillation } \\
\quad 7(8.8 \%)\end{array}$} \\
\hline & $\mathrm{Mean}_{ \pm} \mathrm{SD}$ & D & & $\mathrm{P}$ & 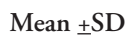 & $P$ & SD & $\mathrm{P}$ & SD & 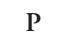 & SD & 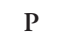 & $D$ & $P$ \\
\hline Cnergy & $3 \pm 1.46$ & & \pm \pm 1.37 & 0.86 & $49 \pm 1.53$ & 0.70 & $1 \pm 1.56$ & 0.12 & 3 & 0.92 & $50 \pm 1.61$ & 82 & $7 \pm 1.71$ & 0.09 \\
\hline & & & & .30 & $78 \pm 1.40$ & 0.83 & $33 \pm 1.57$ & 19 & & 0.99 & & 68 & & 0.22 \\
\hline & & & & & & & & & & & & & & 0.18 \\
\hline & $4+14$ & $0.01^{*}$ & \pm 1.45 & 0.54 & $3 \pm 1.54$ & 0.81 & $2 \pm 1.35$ & 0.02 & 34 & 0.84 & \pm \pm 1.46 & 0.22 & 86 & 0.82 \\
\hline & 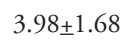 & 0.37 & & 0.14 & $0 \pm 1.84$ & 0.27 & & 0.36 & & 0.72 & \pm 2.40 & 0.17 & $65 \pm 1.49$ & $0.009^{*}$ \\
\hline & $8 \pm 1.44$ & 0.11 & & & $4 \pm 1.53$ & & $3.26 \pm 1.37$ & 0.14 & $3.30 \pm 1.46$ & 0.22 & $4.08 \pm 1.36$ & 0.33 & & $0.03^{*}$ \\
\hline & $68 \pm 1.6$ & $0.01^{*}$ & $1 \pm 1.47$ & 10 & $5 \pm 1.56$ & 0.41 & $69 \pm 1.63$ & 0.51 & $3.83 \pm 1.34$ & 0.81 & $4.40 \pm 1.23$ & 0.22 & $28 \pm 1.83$ & 0.24 \\
\hline & & & & & & & & & & & & 58 & & $0.03^{*}$ \\
\hline & $3.78 \pm 1.47$ & 0.51 & $3.99 \pm 1.35$ & 0.26 & $.06 \pm 1.47$ & 0.25 & $4.15 \pm 1.17$ & 0.34 & & 0.66 & $4.47 \pm 1.12$ & 0.09 & $3.14 \pm 1.77$ & 0.16 \\
\hline nity & 100 & $0.01^{*}$ & $4.08 \pm 1.42$ & 0.61 & $87 \pm 1.62$ & 0.48 & $3.66 \pm 1.54$ & 0.31 & $07 \pm 1.30$ & 0.87 & $0 \pm 1.40$ & 0.33 & $42 \pm 1.81$ & 0.27 \\
\hline & 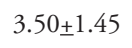 & & $3.68 \pm 1.37$ & & & 0.20 & $3.08 \pm 1.34$ & $0.03^{*}$ & & 0.69 & $4.30 \pm 1.21$ & 0.13 & $2.85 \pm 1.57$ & $0.06^{*}$ \\
\hline & $3.48 \pm 1.5$ & $0.002^{*}$ & & 0.76 & & 0.83 & & 0.06 & & 0.56 & $4.08 \pm 1.36$ & 0.44 & $2.71 \pm 1.60$ & $0.04^{*}$ \\
\hline SS-QOL & $3.53 \pm 1.09$ & $0.004^{*}$ & $3.77 \pm 1.00$ & 0.58 & $3.71 \pm 1.16$ & 0.95 & $3.45 \pm 0.99$ & 0.26 & $3.66 \pm 0.92$ & 0.82 & $4.10 \pm 0.99$ & 0.16 & $2.97 \pm 1.34$ & $0.04^{*}$ \\
\hline
\end{tabular}

P: $p$-value, SS-QOL: stroke specific quality of life scale, $S D$ : standard deviation, ${ }^{*} P$-value is significant at $<0.05$

QOL of patients after stroke was the highest for vision and language domains; the lowest QOL was observed in social roles. ${ }^{18}$

In this study, $57.5 \%$ of the patients were males, and $42.5 \%$ were females. Male predominance has been reported in other studies. ${ }^{910,18,20}$ It was determined post-stroke QOL was almost the same in females and males with no statistical significance in all domains; this result could be due to the unequal sex distribution between the participants, which was similar to result in the study by Samar et al. ${ }^{10}$ However, a study by Pacian et a ${ }^{18}$ showed that females had a significantly higher QOL compared to males ( $p=0.0094)$. However, other studies showed that the functionality of males was better than that of females. ${ }^{20-23}$

Quality of life was significantly higher among patients who were between 26 and 45 years old compared to other age groups with respect to mobility (mean $=4.04$, $p=0.007)$, self-care (mean $=4.58, p=0.022)$, and work/ productivity (mean $=4.60, p=0.008$ ). However, it was determined that there was no significant correlation between the patients' overall QOL and age. Older patients with stroke are more prone to have major negative impacts on stroke morbidity, mortality, and long-term outcomes. ${ }^{24}$ This result has been confirmed by a study conducted by Pacian et al. ${ }^{18}$ Their study presented that patients who were between 61 and 70 years old, had significantly lower QOL related to thinking (1.97), mood (2.29), and family roles (1.98) compared to other participants. Similar to this study, there was no significant correlation between the patients' overall QOL and age. ${ }^{18}$

The majority of patients in this study had an ischemic stroke $(93.8 \%)$. In this study, patients who had ischemic stroke had a significantly higher QOL than patients after hemorrhagic stroke in 2 domains, such as, mood (at the level of 4.17 and $p=0.029)$ and work/productivity (3.87 and $p=0.023)$. However, the overall QOL and the type of stroke were not statistically significant. However, a study conducted in 2015 by Mahran et $\mathrm{al}^{9}$ evaluated 64 stroke survivors; the researches determined that patients with haemorrhagic stroke were associated with higher and better SS-QOL scores compared to patients with ischemic stroke $(154.33 \pm 39.50$ and $126.72 \pm 27.15$, respectively; $p=0.027) .{ }^{9}$ However, a study by Pacian et $\mathrm{al},{ }^{18}$ showed, that the overall QOL of patients with ischemic stroke was significantly higher than that of patients with hemorrhagic stroke (at the level of 2.83 and $p=0.0094$ ).

In this study, patients' QOL significantly depended on stroke recurrence in only 2 domains: mood, and social roles ( $p=0.017$ and 0.033 , respectively). Quality of life was higher in non-recurrent strokes (mood: 4.29, social roles: 3.84 ) compared to recurrent strokes (mood: 3.32, social roles: 3.06). Stroke recurrence affects patient morbidity and mortality which can account 
for a reduction in QOL post-stroke. ${ }^{25}$ However, most SS-QOL domains were not significantly correlated with stroke recurrence. A study conducted in Malaysia showed no significant association between QOL using the SS-QOL score and stroke recurrence. ${ }^{26}$ Moreover, Sturm et al. have observed the effect of stroke recurrence on QOL using another measure for QOL (such as, HRQOL) and observed that recurrent strokes had worse QOL; however, the correlation was not significant. ${ }^{23}$

Similarly, Pacian et al, ${ }^{18}$ did not observe significant correlation between the time passed since a stroke and overall QOL. However, Niemi et $\mathrm{a}^{27}$ showed that post-stroke patients deteriorated over time. The different results reported in other studies can be due to sample heterogeneity. ${ }^{27}$

Regarding patient comorbidity, hypertension was the main risk factor (73.8\%). Previous studies confirm that, hypertension is the main established modifiable risk factor for stroke. ${ }^{28}$ Hypertension showed a significant effect on QOL in most domains $(p<0.05)$. This can be ascribed to the effect of lowering blood pressure on the risk of stroke, which prevents a recurrent stroke. ${ }^{29}$ Hypertension is called the silent disease and it can impact QOL by itself. ${ }^{30}$

However, only atrial fibrillation significantly effected the work/productivity domain $(2.71, p=0.045)$ and overall QOL (1.34, $p=0.040)$. In addition, obesity was significantly correlated with the vision domain (3.089, $p=0.036$ ). Other comorbidities and risk factors (such as, diabetes mellitus, dyslipidemia, ischemic heart disease, and smoking) did not show significant correlation with the overall QOL of stroke patients. In a study conducted in Pakistan, hypertension and smoking were determined to be significantly associated with the QOL of post-stroke patients. ${ }^{31}$ However, Goma et $\mathrm{al}^{10}$ have studied 65 stroke patients and observed no significant correlation between the presence of comorbidity and the SS-QOL score.

This study observed a significant negative linear correlation between the functional disability measured by $\mathrm{mRS}$ and all SS-QOL domains $(p<0.05)$. This result indicates lower QOL with worse functional ability, which is consistent with previously reported studies and can be attributed to the fact that functional ability affects the activities of daily living (ADL), which can affect patients' QOL. In two different studies, Khalid et $\mathrm{al}^{31}$ and Ramos-Lima et $\mathrm{al}^{32}$ have observed similar results.

Study limitations and recommendations. The study has some limitations. First, the study sample was relatively small and confined to the Neurology department attendees in KFHU, which may not accurately resemble the overall Saudi population. Second, the questionnaires were self-reported by the patients; therefore, the probability of misunderstanding cannot be ruled out, which could have affected the results of the study. Moreover, this study is based on a prospective observational study, therefore, it is subject to biases and confounding that might influence the presented results. It is recommended to study a larger sample to ensure reliability and to better reflect the general Saudi population. Moreover, the implementation of post-stroke rehabilitation programs is required to improve the cognitive, physical, social and functional quality of life for those patients.

In conclusion, the importance of performing a comprehensive assessment of the overall QOL in post-stroke patients lies in identifying different aspects of patient's functionality; including mental, social and mobility aspects that are affected by the stroke. Since QOL in post-stroke patients evaluated using SS-QOL has not been studied yet in terms of other variables such as recurrence of stroke, degree of physical disability, comorbidities, and risk factors. This study aimed to assess the overall and domain-specific QOL in post-stroke patients using the SS-QOL scale and to identify variables that may affect the quality of life after stroke. Subsequently, managing these aspects with the help of rehabilitation programs by multidisciplinary teams, will result in healthier outcomes in terms of therapeutic efficacy and, improvement in patients' psychosocial aspects and satisfaction.

Acknowledgment. We wish to thank the College of Medicine, Imam Abdulrahman Bin Faisal, King Fahad Hospital of the University, Al Khobar, Saudi Arabia for supporting this research. We extend our gratitude to Khalid Alhajri, Abdulaziz Alwahaimed, Yazan Aleisawy, Abdulhadi Alghamdi, Raed Alghirash, Ahmed Alherz, and Ammar Bukhamsin who have helped us immensely in data collection, lastly we would like to thank Falcon Scientific Editing (www.falconediting.com) for English language editing.

\section{References}

1. Serda EM, Bozkurt M, Karakoc M, Çağlayan M, Akdeniz D, Oktayoğlu P, et al. Determining quality of life and associated factors in patients with stroke. Turk J Phys Med Rehab 2015;61:148-154.

2. Robert A, Zamzami M. Stroke in Saudi Arabia: a review of the recent literature. Pan Afr Med J 2014; 17: 14

3. Johnson W, Onuma O, Owolabi M, Sachdev S. Stroke: a global response is needed. Bull World Health Organ 2016; 94: 634-634A.

4. King RB. Quality of life after stroke. Stroke 1996; 27: 1467-1472. 
5. Kim P, Warren S, Madill H, Hadley M. Quality of life of stroke survivors. Qual Life Res 1999; 8: 293-301.

6. Laurent K, De Sèze MP, Delleci C, Koleck M, Dehail P, Orgogozo JM, et al. Assessment of quality of life in stroke patients with hemiplegia. Ann Phys Rehabil Med 2011; 54 : 376-390.

7. Fuhrer MJ. Subjectifying quality of life as a medical rehabilitation outcome. Disabil Rehabil 2000; 22: 481-489.

8. Cruz-Cruz C, Martinez-Nuñez J, Perez M, Kravzov-Jinich J, Ríos-Castañeda C, Altagracia-Martinez M. Evaluation of the stroke-specific quality-of-life (SSQOL) scale in Mexico: a preliminary approach. Value Health Reg Issues 2013; 2: 392-397.

9. Mahran SA, Abdulrahman MA, Janbi FS, Jamalellail RA. The health-related quality of life in stroke survivors: clinical, functional, and psychosocial correlate. Egypt Rheumatol Rehabil 2015; 42: 188-195.

10. Goma SH. Mahran S, Mahran D, El-Hakeim E, Ghandour A. Multicenter Assessment of Health-Related Quality of Life (HRQOL) Among Stroke Survivor. J Neurol Neurosci 2016; 7: 96.

11. Abdulla FA, Al-Khamis FA, Alsulaiman AA, Alshami AM. Psychometric properties of an Arabic version of the fatigue severity scale in patients with stroke. Top Stroke Rehabil 2019; 26: 448-455.

12. Sallam SA, Al-Khamis FA, Muaidi QI, Abdulla FA. Translation and validation of the stroke specific quality of life scale into Arabic. NeuroRehabilitation 2019; 44: 283-293.

13. Williams LS, Weinberger M, Harris LE, Clark DO, Biller J. Development of a stroke specific quality of life scale. Stroke 1999; 30: 1362-1369.

14. The Internet Stroke Center's [Internet]. The Internet Stroke Center's; 2020 [UPDATED 2020. Cited 2019 October 7]. Available from URL: http://www.strokecenter.org/wp-content/ uploads/2011/08/modified_rankin.pdf

15. Tsang S, Royse CF, Terkawi AS. Guidelines for developing, translating, and validating a questionnaire in perioperative and pain medicine. Saudi J Anaesth 2017; 11 (5 Suppl 1): 80-89.

16. Opara J, Jaracz K. Quality of life of post-stroke patients and their caregivers. J Med Life 2010; 3: 216-220.

17. Pedersen PM, Vinter K, Olsen TS. Tom Skyhøj Olsen. Aphasia after stroke: type, severity and prognosis. Cerebrovasc Dis 2004; 17: 35-43.

18. Pacian A, Kulik TB, Bednarz J, Kaczoruk M, Kawiak-Jawor E. Quality of Life Assessment in Post-Stroke Patients. Pielegniarstwo XXI wieku/Nursing in the 21st Century 2018; 17: $12-22$.
19. Hopman W, Verner J. Quality of life during and after inpatient stroke rehabilitation. Stroke 2003; 34: 801-805.

20. Mudaliar M, Yiragamreddy S, Tejashwani P, Umapathi S, Sake N, Sharma S. Quality of Life in Stroke Patients Using SSQoL Scale and Barthel Index. Indian Journal of Pharmacy Practice 2018; 11: 44-50.

21. Gargano JW, Reeves MJ. Sex differences in stroke recovery and stroke-specific quality of life: results from a statewide stroke registry. Stroke 2007; 38: 2541-2548.

22. Carod-Artal F, González-Gutiérrez J, Herrero J, Horan T, Seijas E. Functional recovery and instrumental activities of daily living: follow-up 1-year after treatment in a stroke unit. Brain Inj 2002; 16: 207-216.

23. Paul SL, Sturm JW, Dewey HM, Donnan GA, Macdonell RA, Thrift AG. Long-term outcome in the North East Melbourne Stroke Incidence Study: predictors of quality of life at 5 years after stroke. Stroke 2005; 36: 2082-2086.

24. Edwardson M. Overview of ischemic stroke prognosis in adults [Internet]. UpToDate [Updated 2019. Cited 22020 April 2]. Available from URL: https://www.uptodate.com/contents/ ischemic-stroke-prognosis-in-adults

25. Aarnio K, Haapaniemi E, Melkas S, Kaste M, Tatlisumak T, Putaala J. Long-term. mortality after first-ever and recurrent stroke in young adults. Stroke 2014; 45: 2670-2676.

26. Nor MA, Aziz NA, Saperi BS, Aljunid SM. Functional limitation and health-related quality of life, and associated factors among long term stroke survivors in a Malaysian community. Med J Malaysia 2016; 71: 313-321.

27. Niemi M, Laaksonen R, Kotila M, Waltimo O. Quality of life 4 years after stroke. Stroke 1988; 19: 1101-1107.28

28. Boehme AK, Esenwa C, Elkind MS. Stroke risk factors, genetics, and prevention. Circ Res 2017; 120: 472-495.

29. Aiyagari V, Gorelick PB. Management of blood pressure for acute and recurrent stroke. Stroke 2009; 40: 2251-2256.

30. Carvalho MV, Siqueira LB, Sousa AL, Jardim PC. The influence of hypertension on quality of life. Arq Bras Cardiol 2013; 100: 164-174.

31. Khalid W, Rozi S, Ali TS, Azam I, Mullen MT, Illyas S, et al. Quality of life after stroke in Pakistan. BMC Neurol 2016; 16: 250 .

32. Ramos-Lima MJ, Brasileiro ID, Lima TL, Braga-Neto P. Quality of life after stroke: impact of clinical and sociodemographic factors. Clinics (Sáo Paulo) 2018; 73: e417. 